\title{
DILEMAS INSURGENTES NO ESPORTE: AS PRÁTICAS ESPORTIVAS DISSONANTES
}

\author{
DILEMAS INSURGENTES EN EL DEPORTE: LAS PRÁCTICAS DEPORTIVAS \\ DISONANTES
}

INSURGENT DILEMMAS ON SPORTS: DISSONANT SPORT PRACTICES

\section{Wagner Xavier Camargo*}

\section{Palavras-chave Corporalidades disruptivas. Gay Games. Jogos Paralímpicos. Etnografia.}

Palabras clave Corporalidades disruptivas. Gay Games. Juegos Paralímpicos. Etnografía
Keywords Disruptive Corporealities. Gay Games. Paralympics. Ethnography.
Resumo: Como produto da modernidade e fenômeno em franco desenvolvimento no século $\mathrm{XX}$, o esporte igualmente foi afetado pelas reivindicações dos movimentos revolucionários dos anos 1960 e, assim, se esfacelou em múltiplas expressões. Esta pesquisa se preocupa com duas delas em particular: competições esportivas de atletas "com deficiência" (notadamente os Jogos Paralímpicos) e torneios em que lésbicas, gays, bissexuais e pessoas trans (LGBT) competem entre si (Gay e OutGames). O objetivo é ponderar sobre corpos em ação por meio do que almejo denominar "práticas esportivas dissonantes", para discutir em que medida tais práticas teriam potencial disruptivo em relação a uma normatividade instituída. A contribuição justamente consistirá em pensar antropologicamente em que medida essas práticas estariam no esporte mainstream imiscuídas/representadas, abrindo possíveis reconsiderações sobre ele.

Resumen: Como producto de la modernidad y fenómeno de rápido desarrollo en el siglo XX, el deporte también ha sido afectado por las demandas de los movimientos revolucionarios de la década de 1960 y, por lo tanto, se rompió en múltiples expresiones. Esta investigación estudia dos de esas expresiones: el deporte para "minusválidos" (en particular los Juegos Paralímpicos) y los juegos donde compiten lesbianas, homosexuales, bisexuales y transexuales (LGBT) (Gay y Outgames). El objetivo es reflexionar sobre los cuerpos en acción por lo que llamo de "prácticas deportivas disonantes", para discutir hasta donde estas prácticas tienen potencial para perturbar la normativa establecida. La contribución de la investigación es pensar en qué medida tales prácticas están representadas en el propio deporte mainstream, abriendo reconsideraciones sobre él mismo.

\begin{abstract}
As a product of modernity and a phenomenon that saw full development during the 20th century, sport has also been affected by the demands of revolutionary movements of the 1960s and therefore split in multiple expressions. This research is concerned with two of them in particular, namely, elite sports for disabled athletes - notably the Paralympic Games - and tournaments where lesbian, gay, bisexual and transgender people (LGBT) compete together-Gay and Outgames. The aim is to discuss bodies in action through what I call "dissonant sports practices", in order to debate to what extent such practices could disrupt established normativity. The study's contributes to thinking anthropologically about the extent to which those practices would be included/represented in mainstream sports, thus opening reconsiderations about them.
\end{abstract}

*Universidade Federal de São Carlos (UFSCar). São Carlos, SP, Brasil. E-mail: camargow@ymail.com

Recebido em: 03-08-2016 Aprovado em: 28-10-2016 (c) (1) (8) Licence 


\section{INTRODUÇÃO}

Pouco antes dos Jogos Olímpicos Rio-2016 muito se comentava na mídia sobre performances esportivas de homens e mulheres atletas que, vindos dos cinco continentes e de cerca de duzentos países, provavelmente quebrariam recordes, melhorariam marcas e, como consequência, ganhariam muitas medalhas. As expectativas com relação ao espetáculo de feitos provinham de países, comitês esportivos, treinadores(as), familiares, torcedores(as), amigos(as) e mesmo dos(as) próprios(as) atletas. Desde a reinstauração e recriação do processo competitivo chamado "Olimpíadas" em 1896 por Pierre de Fredi (ou Barão de Coubertin) que o mundo fica em polvorosa com a realização dos Jogos Olímpicos (COLLI, 2004), hoje considerados um "megaevento global".

Contudo, o universo esportivo olímpico se modificou muito desde Coubertin: a tecnologia das guerras o transformou, modalidades surgiram, implementos mudaram, dimensões foram agregadas, uma geopolítica de resultados esportivos se desenhou durante grande parte do século XX e novos sujeitos políticos apareceram - as mulheres são cada vez mais ativas e presentes; mas não se trata apenas delas.

Os movimentos de questionamento da ordem estabelecida, nos ventos que sopravam no mundo nos anos 1960, demandavam direitos de existência a atores excluídos dos processos políticos decisórios. E no esporte isso não foi diferente. É nessa mesma década que os Jogos Paralímpicos foram criados para pessoas com deficiências físicas, mentais e sensoriais, passando a fazer parte do programa de competições internacionais (BAILEY, 2008). E, em meados dos anos 1980, foram criados os "Jogos Gays" (ou Gay Games, em inglês), que tendo status, mas não o título de "Olimpíadas", edificaram-se para dar lugar à prática esportiva de gays, lésbicas, bissexuais e pessoas trans (LGBT), alijados dos meios competitivos demasiadamente heteronormativos. ${ }^{1}$ Ambos os modelos visavam encenar o esporte de alto nível para esses grupos específicos de indivíduos.

"Paralimpíadas" e "Gay Games" são, obviamente, diferentes expressões de esporte que se materializam, com certa periodicidade, nos calendários do sistema esportivo globalizado. Em que pese os(as) próprios(as) atletas LGBT e deficientes não saberem/reconhecerem a existência ou nem sempre conferirem legitimidade aos modelos esportivos de que eles mesmos participam, essas estruturas esportivas oferecem interessantes insights para tratar o próprio esporte convencional.

Quando me refiro ao "universo convencional do esporte" estou nomeando um circuito esportivo que engloba práticas multiesportivas do olimpismo, conforme definidas pela Carta Olímpica em 1896, por Coubertin. Ou ainda, como diria Norbert Elias (1994), esse fenômeno seria o "esporte moderno", ou ressignificando aos tempos mais atuais da mundialização das atividades esportivas, o "sistema esportivo global", de acordo com a definição de Carmen Rial (2008).

Mais tarde voltarei ao detalhamento dos fenômenos esportivos em consideração; agora, o que quero chamar atenção é que as práticas corporais e esportivas inscritas nesses dois modelos competitivos apresentam (ou podem apresentar) um substrato comum, qual

1 Duas observações importantes: a) os Gay Games não têm status de Olimpíadas porque o Comitê Olímpico Norte-americano impugnou 0 termo numa disputa judicial, ainda nos anos 1980 (WADDEL; SCHAAP, 1996; YOUNG, 1995); b) Tendo feito etnografia em várias competições internacionais reconheço que muitos sujeitos são invisibilizados pela maciça presença de homens gays: lésbicas, pessoas trans ou intersex "gravitam" à margem das competições. 
seja, a não reprodução de movimentos canonizados pelo esporte com vistas à performance, mas mesmo assim, obtenção de eficiência do gesto atlético. 0 que eu denominarei "práticas esportivas dissonantes" seriam manifestações atléticas que não se enquadrariam nos moldes de reprodutibilidade técnica dos gestos corporais do universo esportivo convencional e que, mesmo assim, obtêm resultados.

Nominarei, de outra parte, corpos dissonantes aqueles que se colocam nos limites fronteiriços dos corpos normativos, considerados desviantes da "norma" ou "abjetos"2, que se afastam, por exemplo, dos idealizados padrões de beleza, estética e/ou eficiência propostos pelas sociedades ocidentais contemporâneas e que estão em vigor em disputas esportivas, como Jogos Olímpicos e Mundiais.

Aqui talvez valha a pena um comentário rápido sobre o corpo: Mary Douglas (1976) sugere que os contornos do "corpo" são determinados por meio de marcações, as quais buscam estabelecer códigos particulares de coerência sociocultural. Ela sugere que o limite desse corpo nunca é meramente material, mas sua superfície é constantemente significada por transgressões e tabus preestabelecidos. De sua parte, Judith Butler $(2003$, p.59) aponta para o caráter construído desse "corpo", que não deve ser tomado como uma superfície à espera de significação, mas como "um conjunto de fronteiras, individuais e sociais, politicamente significadas e mantidas".

Para levar em conta as práticas esportivas dissonantes faço uma eleição tanto aleatória, quanto produto de minhas vivências como antropólogo em distintos espaços esportivos e penso ser necessário um distanciamento (antropológico) do saber sobre o "esporte LGBT" e o "paradesporto" (esporte de pessoas com deficiência). E, ao mesmo tempo, considero fundamental levar em conta três premissas:

a) Identificar corporalidades não normativas significa mapear corporalidades não consonantes com as hegemônicas vigentes. Pressuponho, igualmente, afastar certa tautologia na explicação de "corpos não normativos" em ambientes esportivos "não convencionais". Segundo Robert McRuer (2006), há uma corponormatividade em voga na sociedade e, mais do que isso, uma prerrogativa de que os corpos são compulsoriamente hábeis e heterossexuais. Os corpos não normativos podem estar em qualquer lugar e o que chamo atenção é para a performance desses corpos no meio esportivo não convencional.

b) Aceitar a possibilidade de ocorrência das práticas esportivas dissonantes: e, portanto, se estabeleceria uma tensão entre, de um lado, o assimilacionismo dos sujeitos em relação às práticas esportivas convencionais (como padrões estabelecidos) - com consequente reprodução das chamadas "técnicas corporais" (MAUSS, 2003) - e, de outro, a potencial subversão delas. Explico melhor: tanto pessoas com deficiência como LGBTs têm à disposição um modus operandi que determina como seus esportes devem ser praticados. No primeiro caso, adaptações podem ser feitas (o que caracterizaria uma mudança no gesto atlético da "técnica conhecida", adequando a uma classificação funcional do organismo) com vistas a obter um rendimento expressivo; o mesmo pode ser pensado no "esporte LGBT", que performatizado com uma roupa não apropriada ou mesmo expressado de modo excêntrico (por exemplo, com gritos estridentes ao pular sobre barreiras, numa prova de 400 metros) pode surtir 0 efeito esperado. 
c) Analisar o significado simbólico da realização de tais práticas: há que se considerar a ambivalência presente nas práticas esportivas em questão quando por ocasião de suas ocorrências. Ao mesmo tempo em que homossexuais masculinos competem entre si e querem ser reconhecidos por "conseguirem desempenhar o esporte tão habilmente como homens heterossexuais" (lapso assimilacionista de reconhecimento), a ocupação dos espaços esportivos por tais indivíduos, por exemplo, tem um significado simbólico importante dentro do "mundo masculino do esporte".

Considero, dessa forma, essas elaborações mentais essenciais na busca pelo entendimento do que nomeio práticas esportivas dissonantes, referentes às pessoas com deficiência e LGBT. Para problematizar ainda mais, vou propor considerações sobre tais práticas. A ideia de fundo é pensar em um substrato comum entre os dois modelos esportivos, a fim de ventilar possível potencial disruptivo na expressão do esporte em voga na sociedade contemporânea. $^{3}$

Ainda aqui vale uma observação: dissonância e dissidência são interessantes nominações neste contexto tratado e o termo queer pode ser útil, em certa medida, porque inspira deslegitimação, instala a dúvida e traz o "xingamento" - queer sempre habitou o domínio do estranho, do ilegítimo, do esquisito na língua inglesa e se legitima pelo avesso; nos anos 1990 foi apropriado pelo movimento Queer Nation como forma de orgulho e autorreferência (GATTI, 2011). ${ }^{4}$ Portanto, as práticas esportivas dissonantes são práticas queer, em certo sentido.

Adianto que, mais do que identificar potencial subversivo ou algo que o valha, o que está em jogo é pensar, no limite, novas possibilidades de prática (para, inclusive, pensar novos modelos de esporte). Não partirei da premissa teórica de que sujeitos e práticas necessariamente subvertem (ou não) sistemas que ocupam; muito menos indagarei se "pessoas LGBT", por exemplo, subvertem ou não o contexto esportivo (o chamado queering the context), que na literatura já foi, de vários modos, explorado (ENG, 2008 e 2006; DAVIDSON, 2006; JARVIS, 2006; TRAVERS, 2006).

Procuro, a seguir, detalhar e esgarçar os modelos esportivos "alternativos" - ou marginais no sistema esportivo global, como os considero - a fim de mapear suas propostas, contradições e fissuras, e inter-relacionar seus elementos com outras práticas sociais. No caso LGBT as festas que ocorrem associadas aos eventos esportivos são importantes elementos de sociabilidade (ou homossociabilidade) relativos à coesão grupal a serem considerados. Assim, tento compreender melhor como os universos LGBT e paradesportivo se estruturam, uma vez que as competições atléticas permitem pensar na compreensão do esporte e de suas representações a partir do ambiente em que se desenvolvem.

\section{RETOMANDO O QUE SE ENTENDE POR "ESPORTE LGBT" E "PARADESPORTO": TUDO JUNTO E MISTURADO}

Em primeiro lugar e antes de tudo, não existe "esporte LGBT". Essa expressão a que todos(as) os(as) envolvidos(as) se referem (LGBT sports ou gay sports, em inglês) é um

3 Ou "atos subversivos", como pondera reflexivamente Butler (2003). Para Marie-Hélène Bourcier (2001), práticas disruptivas (ou subversivas) encampam políticas de representação e de performatividade, e desnaturalizam regimes sexuais, de gêneros, disciplinares, tornando-se lugares de (re)politização. 
equívoco, pois o que se tem são pessoas que praticam esportes e que não se identificam com a heterossexualidade compulsória (RICH, 1999). Os gestos técnicos nas modalidades esportivas em si e os implementos não sofrem adaptações ou variações, a não ser pelas performances dos corpos, e aí já se adentra na discussão que teço nesta pesquisa. De outra parte, o paradesporto (e o esporte paralímpico, como expressão máxima desse) existe a partir de modalidades esportivas chamadas de "adaptadas" ou "não adaptadas", isto é, esportes que se adaptam mediante a funcionalidade dos corpos de pessoas com deficiência (por exemplo, 0 futebol para amputados é praticado com muletas e o basquete para paralisados/amputados é jogado em cadeiras de rodas, para distintos níveis de lesão) ou os que acontecem do mesmo modo que conhecemos (por exemplo, as corridas de atletismo para pessoas com deficiência intelectual). ${ }^{5}$

Os torneios esportivos LGBT, por sua vez, são eventos de alcance global e, frequentemente, organizados por duas entidades internacionais. Os Gay Games são realizados pela Federação dos Gay Games (FGG), a cada quatro anos, em co-organização com a cidade-sede detentora do direito de realizar o evento (SYMONS, 2010). E, por outro lado, a Associação Esportiva Internacional de Gays e Lésbicas (GLISA) organiza, desde 2006, um campeonato mundial denominado World OutGames, também num calendário quadrienal, e que se estabeleceu como uma nova referência em termos de torneio mundial (CAMARGO; RIAL, 2011). Enquanto os primeiros focam no esporte-competição e desde o início estabeleceram isso como carro-chefe, os segundos baseiam-se na celebração da cultura, da política e dos direitos humanos de pessoas socialmente excluídas.

No que concerne ao esporte praticado por "pessoas com deficiência" há um crescente aprimoramento em voga desde os anos 1960, quando foram organizados os primeiros Jogos Paralímpicos em Roma, na Itália, que contaram com a participação de 23 países e cerca de 400 atletas, no mesmo local e ano em que ocorreram os XVII Jogos Olímpicos de Verão (INTERNATIONAL PARALYMPIC COMMITTEE, 2015). ${ }^{6}$ A cada nova edição, o Brasil estabelece um abismo entre os resultados dos(as) atletas no paralimpismo em comparação ao olimpismo: ao passo que nos Jogos Olímpicos as marcas, recordes e medalhas são pouco expressivos e deixam o país longe de qualquer situação de importância na comparação com nações desenvolvidas. Nos Paralímpicos o país se encontra entre os primeiros do ranking de medalhas e há um projeto em andamento que almejava, para o Rio-2016, colocá-lo entre as maiores potências mundiais desse tipo de expressão esportiva. ${ }^{7}$

Ambos os tipos de competições participam do "sistema esportivo global" (RIAL, 2008) e são um produto das sociedades modernas, do mesmo modo que o esporte é considerado (ELIAS, 1994), como já fiz referência. Assim como esse último foi difundido e assimilado no mundo no último século, as competições paralímpicas e LGBT funcionam como projetos políticos de reinvenção e reafirmações de ficções identitárias - uma contrapositória ao corpo eficiente e a outra avessa à normatização da sexualidade.

\footnotetext{
5 Aqui talvez a discussão seja um pouco mais complexa, pois há ainda os esportes sem adaptação, que foram criados para "pessoas com deficiência", como é o caso do goalball, esporte de atletas com deficiências visuais, Não cabe aqui tal aprofundamento.

60 desenvolvimento do hoje nominado "esporte paralímpico" vem desde fins da II Guerra Mundial, quando as clínicas de reabilitação (principalmente em países europeus envolvidos no conflito) elaboraram formas de ressocialização via esporte de indivíduos lesionados. Isso aconteceu de modo pronunciado na Inglaterra, no Hospital de Stoke Mandeville, onde Ludwig Guttmann criou um centro para lesionados medulares e passou, em pouco tempo, a aplicar exercícios físicos e esportes a eles (BAILEY, 2008, STROHKENDL, 1996). Apesar da sincronização de sedes entre Jogos Olímpicos e Paralímpicos em 1960, tal fato só vai mesmo se tornar prevalente e oficial nas edições partir de Seul, na Coreia do Sul (em 1988)

7 Esse projeto teve início em 1995, com a criação do Comitê Paraolímpico Brasileiro ou CPB (CAMARGO, 2000) e a meta era colocar o país entre as cinco maiores potências paralímpicas mundiais em número de medalhas.
} 
Historicamente, em países como Estados Unidos, Canadá, Austrália e alguns outros da Europa Ocidental, os eventos esportivos LGBT têm certa tradição, datando de início dos anos 1980 (BOSCH; BRAUN, 2005; WADDELL; SCHAAP, 1996). Na atualidade, outros países sem tradição na realização deles emergem como bastante interessados em seu planejamento e execução - notadamente Brasil, Filipinas, México e Argentina. ${ }^{8}$ Tais competições são eventos autodenominados "culturais e esportivos", que oferecem variadas atividades e, dentre elas, o esporte-competição é o carro-chefe, sendo diferencial o OutGames devido à realização de uma Conferência de Direitos Humanos LGBT, previamente à semana de contendas. $O$ público participante de desses jogos é bem heterogêneo, sendo as atividades praticadas por sujeitos que se autoidentificam como gays, lésbicas, bissexuais, transexuais, travestis, transgêneros, intersex e queers.

Já os jogos e torneios voltados para "pessoas com deficiência" possuem etapas similares aos (e muitas vezes concomitantes com) circuitos de competições de atletas sem deficiência. São campeonatos de modalidades individuais ou coletivas, adaptadas ou não, que se apresentam em nível regional, estadual, nacional, latino-americano, pan-americano, mundial e paralímpico. A literatura pouco tem registrado, mas na prática há também participação de "pessoas com deficiência" em competições comuns - como meetings de atletismo ou natação, campeonatos regionais/estaduais de judô, e mesmo em âmbito internacional, como foi o caso de Oscar Pistorius na ocasião das Olimpíadas de Londres-2012.

Os eventos esportivos LGBT variam muito em nível técnico (performance atlética): há torneios locais (como jogos municipais ou apresentações recreativas por fatores de comemoração de eventos) ${ }^{9}$, os nacionais (como o I Campeonato LGBT da Bolívia, ocorrido em 2008), os regionais (estendendo-se por uma ampla área, como II North American OutGames, de 2011), e mesmo os continentais (como os EuroGames, de realização regular desde 1992)..$^{10}$

Em competições esportivas globais como Copas do Mundo de Futebol Masculino ou Jogos Olímpicos (e, por conseguinte, os Paralímpicos), o local e o global se articulam na construção dos discursos identitários sobre a Nação (GASTALDO, 2007), em competições de LGBTs há um processo semelhante, porém não exatamente idêntico: há grupos que vestem camisas representativas de suas cidades e outros que usam cores nacionais. No torneio de voleibol dos Gay Games em Colônia-2010, ao mesmo tempo em que podiam ser encontradas equipes como "Magnum Houston" ou "London Volley" (representando, explicitamente, as cidades que aparecem nos nomes), havia também outras como "Wonder Thai" e "Aztecas Mexico", em referências, respectivamente, à Tailândia e ao México e, portanto, representando países.

Essa flexibilidade de representação é permitida nesses contextos e amplamente aceita. Os discursos sobre "ser mexicano", "ser tailandês" ou "ser brasileiro" - só para citar alguns dos que os encampam - são essencialismos identitários e estabelecem as velhas (e conhecidas) fronteiras frente à alteridade. Como as identidades não podem ser tratadas de forma monolítica ou estável (HALL, 1992), e a problemática em torno das "identidades de

8 No Brasil, o CDG (Comitê Desportivo Gay) - organização similar ao COB (Comitê Olímpico Brasileiro) ou CPB (Comitê Paralímpico Brasileiro) - postulou a candidatura brasileira para o Gay Games de 2018, mas o país foi eliminado na primeira rodada de votação.

9 Para comemorar o Orgulho Gay, Florianópolis realiza todo ano os Diversity Games, ou Jogos da Diversidade, que acontecem geralmente em três dias.

10 Os EuroGames, competições entre países europeus, em geral ocorrem a cada dois anos ou quando não se tem outro evento esportivo específico internacional. As decisões sobre sedes, datas e viabilidade na realização são discutidas pela Federação Esportiva Europeia Gay e Lésbica (EGLSF), cuja assembleia é anual, em algum/alguma país/cidade escolhidos na mesma ocasião. 
gênero" fervilha no conjunto dos discursos individuais e coletivos em tais contextos, ocorre nas competições LGBT o que se poderia designar como "dessacralização dos sentimentos nacionais" (SOARES; VAZ, 2009). Ou seja, aquilo que é um ponto importante de estruturação e de manutenção das paixões coletivas no esporte convencional (e, também em certa medida, no esporte paralímpico) em escala planetária - inclusive movimentando bilhões de dólares em produtos, imagens e serviços que representariam a Nação - no caso daquelas competições é inexpressivo, pois os "sentimentos nacionais", quando aparecem, estão completamente fora do panorama midiático (RIAL, 2008; APPADURAI, 1994) e mesmo das lógicas mercadológicas esportivas globais.

No entanto, por apresentarem a característica de eventos globais e serem amplamente atendidas por atletas de todos os continentes, as competições LGBT e as paralímpicas se configuram como um estímulo para refletir sobre processos de assimilação/normatização, de estabelecimento de padrões de corponormatividade (McRUER; WILKERSON, 2002) ou rompimento destes, de territorialização/desterritorialização de gênero e de itinerância de desejos (CAMARGO, 2015; CAMARGO; RIAL, 2011).

Proponho pensar o caso do atleta Oscar Pistorius, corredor biamputado sul-africano, "multicampeão" paralímpico devido aos seus resultados excepcionais nas provas de 100, 200 e 400 metros rasos nas Paralimpíadas de Beijing-2008. Em fins de 2011 ele se classificou no Mundial de Atletismo da IAAF na Coreia do Sul, para participar dos Jogos Olímpicos Londres-2012 como atleta (BBC SPORT, 2011). Apesar do feito, e mesmo tendo competido junto com a equipe sul-africana dos referidos jogos, a deficiência o colocou, a todo tempo, como um corpo estranho (ou "desviante") no universo das práticas esportivas convencionais.

Contudo, com sua participação em Londres ele colocou em oposição, da esfera pessoal à institucional, federações de esporte a IAAF, além dos comitês Olímpico e Paralímpico Internacionais, atletas com e sem deficiências, e, no limite, questionou o modo como eficiência/ deficiência são postadas na sociedade contemporânea e encampadas pelo mundo esportivo. Esse precedente, nunca antes materializado dessa forma e na proporção que o fora, é um marco importantíssimo nas considerações do que discuto aqui.

Para além de meras especulações, parece haver duas questões importantes em tela: por um lado, há o atleta com deficiência e sua prótese (aqui se pode pensar em deficiência e diversas formas de protetização), que colocam em xeque o modo como o mundo esportivo é estruturado e organizado, fazendo aparecer fissuras de uma manifestação já obsoleta e propondo, em perspectiva, novos modelos de organização da prática esportiva, possivelmente mesclando habilidade e tecnologia. Por outro lado - e este ponto é algo mais crítico -, a proliferação de casos como o de Pistorius, ou seja, de atletas com deficiência tão ou mais "hábeis" do que os comuns, pode tensionar ainda mais o universo dos corpos: "eficientes" versus "deficientes", ou dos "mais normais" versus os "menos normais", ou ainda, corpos normativos ou "desejados" versus corpos dissonantes ou "indesejáveis".

Pistorius potencializa o que chamo de práticas esportivas dissonantes do meio esportivo. A tensão criada entre olimpismo/paralimpismo, conforme destaquei, pode abrir a discussão no esporte acerca da "falência de modelos". Ou, dito de outra forma, poderia o esporte paralímpico fornecer uma pista de transformação do mundo esportivo a partir da potencialização de outros parâmetros de competição entre atletas com e sem deficiência? 
No tocante ao universo do "esporte LGBT" há, igualmente, considerações a serem feitas. Se, por um lado, há atletas que dele participam com a clara intenção de competirem e obterem resultados (segundo a lógica de rendimento do esporte convencional), por outro, há participantes que têm outros objetivos, como o de conhecerem potenciais companheiros(as), frequentarem festas, correrem fantasiados, fazerem performances grupais musicais, ou ainda, imprimirem certas referências próprias por meio do esporte. Foi o que fez 0 grupo a seguir apresentado numa foto tirada por mim, no final do revezamento 4 × 100 metros rasos, nos Gay Games em Cleveland-2014:

Figura 1 - corredores/as da prova de $4 \times 100$ metros

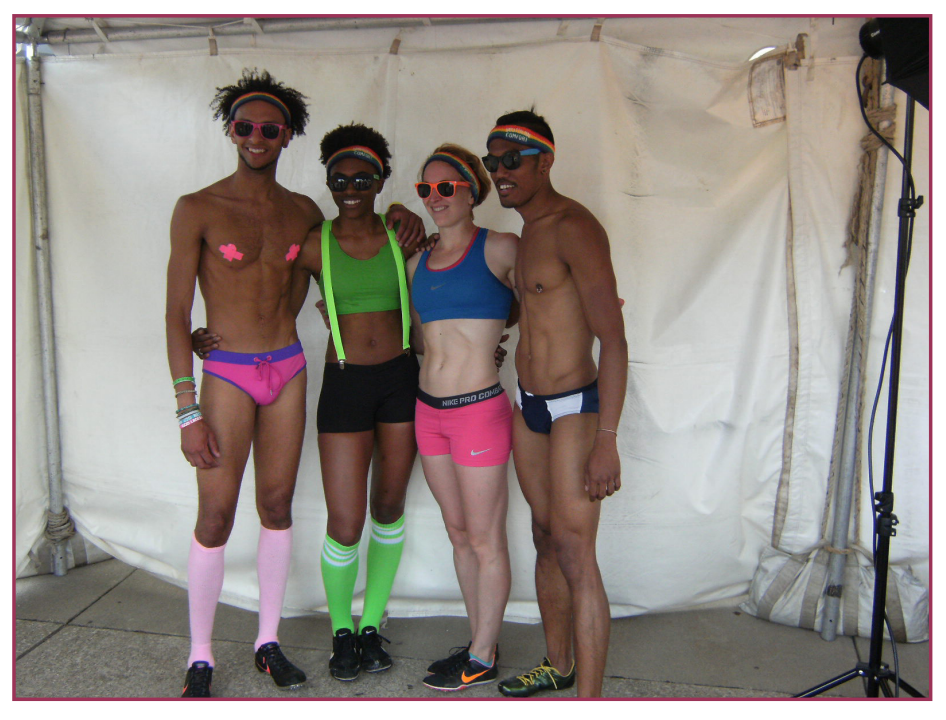

Fonte: acervo autor.

Essa equipe (composta de modo misto) pôde correr, mas não foi considerada na competição. Tanto nos Gay Games quanto nos OutGames as categorias legítimas para manter a "igualdade de chances" são (ainda) a masculina e a feminina. Grupos mistos ou gêneros que não se encaixam no binário "masculino/feminino" não têm legitimidade para competirem. Mas a equipe fez mais do que apenas um show visual; os(as) atletas correram o revezamento num tempo muito similar ao das equipes que estavam na disputa do revezamento 4 × 100 metros.

Devo admitir que, em todas as vezes que fiz etnografia em competições esportivas internacionais, sempre estive interessado nas práticas esportivas de atletas como os(as) mostrados(as), independente de como performatizavam tais gestos atléticos. No entanto, as cenas disruptivas, que faziam algo distinto do esperado, chamavam atenção justamente por trazer a possibilidade de algo novo, tensionando as certezas instituídas e buscadas pelos modelos esportivos LGBT.

Carlos Eduardo Costa (2009), que etnografou torneios universitários no interior de São Paulo, considera o esporte de universitários como práticas corporais com finalidades esportivas, e, similarmente, penso que o "esporte LGBT" pode ser tomado na mesma chave interpretativa. Segundo o autor, as "práticas esportivas universitárias" são atividades "que não poderiam ser classificadas como esporte, mas são disputadas como se fossem" (COSTA, 2009, p. 31-32).

Mais esportivas ou mais festivas, dependendo do formato e da competição, as práticas esportivas de indivíduos LGBTs talvez possam oferecer pistas importantes nas considerações sobre as práticas esportivas dissonantes ou disruptivas. 
Em sua pesquisa, Costa (2009) identificou que os estudantes realizavam "práticas esportivas tradicionais", ou aquilo que era entendido como "práticas representativas do esporte" (dentre as mais comuns eram vôlei, basquete, futebol e rúgbi) e organizavam, igualmente, o que denominou de "práticas alternativas ou excêntricas", isto é, formas distintas do estabelecido pelas regras e que não apenas geravam participação, como momentos de descontração, muito apreciados pelos participantes. Citou como exemplos a "maratoma" (uma corrida em que há o consumo de bebida alcoólica durante um dado percurso que deve ser cumprido) ou o "4 x 100 roupas" (uma corrida de revezamento em que competidores corriam sem roupas).

A maioria dos atletas LGBT, por sua vez, apresenta certa resistência em propor "práticas alternativas" em seus cenários esportivos e também não acredito ser produtivo generalizar tal termo para eles. Há forte sentimento assimilacionista com relação ao esporte mainstream e uma reprodução fidedigna de técnicas corporais (lança-se mão de práticas corporais hegemônicas para angariar reconhecimento e legitimidade) e tal aspecto talvez possa ser pensado, de igual maneira, no caso do esporte praticado por pessoas com deficiência.

Resgato, a seguir, um trecho de meu diário de campo, sobre uma prática corporal específica durante torneios LGBT:

Na sexta-feira cheguei para a natação como nos demais dias. Na verdade, não tinha mais motivos para ir, mas havia prometido a AJ que o veria nadar o $1500 \mathrm{~m}$ livre. Ele disse que a prova é chata; porém é só um apoio moral. Ao chegar, uma drag queen pediu-me um ingresso e não entendi. Então me disse que, se não tinha era preciso pagar 20 euros e adquiri-lo na bilheteria. Paguei e entrei. Logo o show começou e um grupo de rapazes entrou na piscina como se fossem fazer um nado sincronizado, porém masculino. Estavam vestidos com maiôs avermelhados, cheios de lantejoulas pink e pedrinhas brilhantes prata. Na cabeça, touquinhas de plástico. Achei o visual cômico, mas aguardei para ver o que rolaria (CADERNO DE CAMPO, 2010).

O showa que me refiro na passagem supracitada chama-se "Pink Flamingo" e é bastante popular durante os Gay Games. É uma espécie de nado sincronizado, porém com homens. Durante a apresentação coreografada à base de uma dance music bastante conhecida do público, os atletas caracterizados com maiôs e toucas rosa/lilás faziam movimentos ritmados, tanto dentro como fora da água. A apresentação acontece, tradicionalmente, no último dia de competições na natação e é atração geral, um momento de descontração, de risos e de confraternização entre nadadores e espectadores(as):

Figura 2 - Pink Flamingo Show

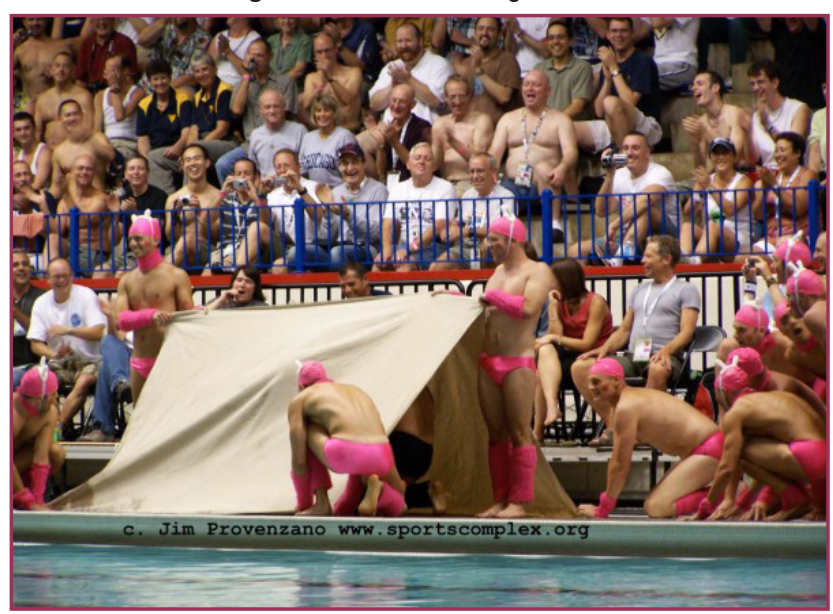

Fonte: Cortesia de James (Jim) Provenzano. 
Penso que tal prática poderia ser diferente. A proposta encampada por alguns atletas nos Gay Games e materializada na estetização do "nado sincronizado para homens", uma modalidade inexistente no esporte convencional, abriria a perspectiva para problematizar as seguintes questões: a) generificação de modalidades esportivas e os motivos culturais de autorização/proibição de performatizar ou não tal modalidade para homens/mulheres; e b) consequente despadronização do alinhamento sexo-gênero-esporte.

O mesmo podemos pensar para o caso da Ginástica Rítmica (GR) desenvolvida no Japão e em alguns países europeus por atletas do gênero masculino (COELHO, 2016; CHIMOT; LOUVEAU, 2010), pois, sendo um esporte "historicamente feminino", a proliferação de torneios masculinos japoneses de GR coloca em xeque a lógica (ilógica) do alinhamento e assignação entre sexo biológico, expectativas de gênero e esporte especifico. Ou ainda, a proposta de realização, também oferecida pelos Gay Games em Colônia 2010, do figure skating (patinação artística) entre casais do mesmo sexo:

Figura 3 - Apresentação figure skating (patinação artística)

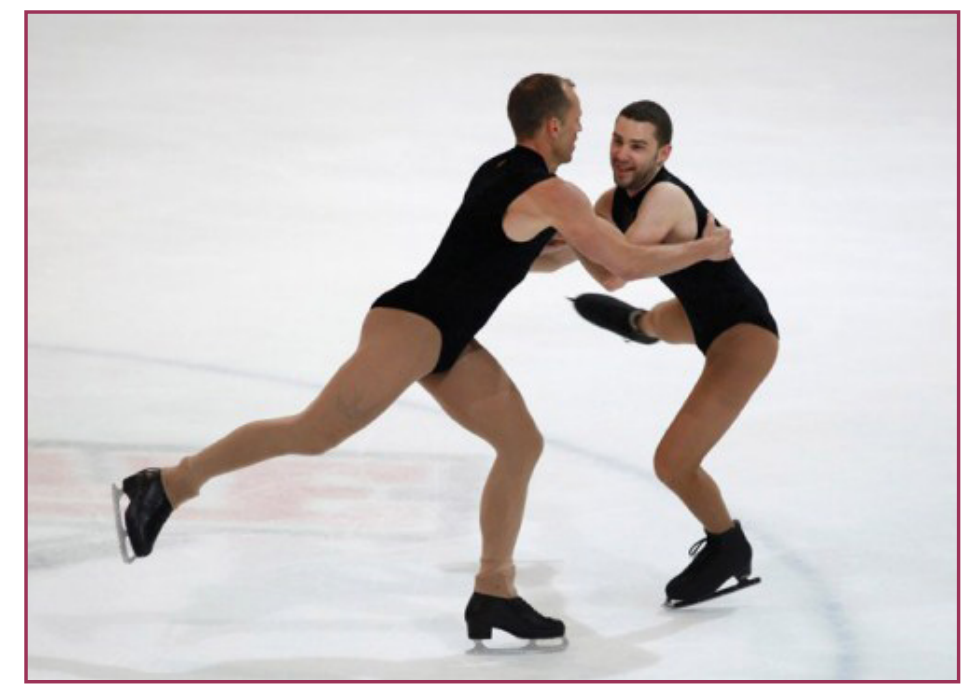

Fonte: Federation of Gay Games (2010)

Note-se que a patinação artística é uma modalidade solo ou, no máximo, composta por casais de sexos opostos. A foto anterior nos mostra uma composição entre dois corpos masculinos, em formação de casal. Além disso, estão usando collants, meias-calças e patins femininos. A proposta, muito ovacionada pelos presentes à época, foi motivo de grande discussão e especulações por parte dos próprios espectadores.

Em que pese haver outras iniciativas (talvez mais radicais) - como a identificada por Brian Pronger (2000), acerca do wrestling (luta grego-romana), onde o objetivo das contendas é sexual -, esses exemplos estabelecem uma tensão entre as práticas esportivas convencionais e as dissonantes, e nos levam a pensar no poder provocativo das exceções ou em um devir disruptivo, que, atrelado à imensa diversidade social e sexual existente entre os sujeitos participantes do mundo esportivo, poderia propor novas reconsiderações sobre o próprio esporte convencional. Talvez tais práticas esportivas dissonantes nos digam mais sobre o normativo esporte do que ele tem dito sobre si. 


\section{3 À PROCURA DE UMA PRÁTICA ESPORTIVA DISSONANTE}

Pensando num futuro em que as categorias "sexo/gênero", "eficiência"/"deficiência", "masculino"/"feminino", "juvenil"/"máster" fossem eliminadas dos sistemas de competição tanto de esportes individuais como coletivos, seria preciso pensar nos modos de pontuação, controle de resultados, classificação e, no limite, seria preciso ressignificar a ideia de competição, do modo como a conhecemos atualmente no esporte-espetáculo.

Da esfera pessoal à institucional, o caso de Pistorius colocou em oposição federações de esporte para deficientes e a IAAF, os comitês Olímpico e Paralímpico Internacionais, atletas com deficiência e sem, e, no limite, questionou o modo como eficiência e deficiência são postadas na sociedade e encampadas pelo mundo do esporte. Na guerra de argumentos pró e contra, foi acusado de "tecnodoping" (MOORES, 2008), ou de se beneficiar de doping tecnológico, mas sobreviveu como agente questionador da estrutura.

Para além da polêmica desse caso específico, acredito haver dois pontos importantes, quais sejam, as formas de protetização da subjetividade (e, portanto, de uma nova produção de sujeito) e as fissuras abertas no modelo esportivo institucionalmente constituído. Eles nos oferecem possibilidades de, no limite, pensar novos modelos de organização esportiva, possivelmente mesclando habilidades, substâncias químicas e tecnologia. E mais: corpos não normativos, como o de Pistorius ou dos patinadores artísticos mostrados anteriormente (sem falar de uma plêiade de outros sujeitos que transitam nesses universos esportivos), colocam em xeque a própria corponormatividade (McRUER; WILKERSON, 2002) e seus contornos instituídos.

Importante dizer, então, que esta pesquisa tentou evitar o uso e a formatação de "modelos totais" de mundo como ferramenta explicativa para a compreensão dos fenômenos que envolvem e são produzidos por sujeitos esportivos (com deficiência e LGBT). Os modelos de competição à disposição não são tomados como efeito do funcionamento de uma engrenagem esportiva mundial (apesar da menção frequente ao sistema esportivo global); mas como ela própria é produtora de pequenos movimentos e novas configurações a partir de relações micro-micro, que se dão quando por contingências dos atores, quando imaginam, compõem e circunscrevem o mundo enquanto uma estrutura macro.

Quando escrevo sobre modelos alternativos de esporte (Gay Games, OutGames ou as Paralimpíadas) estou me referindo a novas formas de territorialização de corpos e desejos. Assim como quando falo de "futebol" ou "torcedores/as e suas manifestações" (como racismo, sexismo e homofobia) estou tratando, sem dúvida, de relações com o campo e com os marcadores sociais que atuam nele/sobre ele - gênero, sexo/sexualidade, "raça"/etnia são alguns deles. Esses corpos que habitam o universo não "corponormativo" trazem à baila o fato que próteses, órteses e objetos outros mudam a configuração de nossas percepções a ponto de nos questionarmos se tais práticas poderiam ser o prenúncio de novas estéticas e novas técnicas corporais no esporte.

\section{REFERÊNCIAS}

APPADURAI, Arjun. Disjunção e diferença na economia cultural global. In: FEATHERSTONE, Mike (coord.). Cultura Global: nacionalismo, globalização e modernidade. Rio de Janeiro: Vozes, 1994. p. 311-327. 
BAILEY, Steve. Athlete first: A history of the Paralympic movement. London: John Wiley \& Sons, 2008.

BOSCH, Heike; BRAUN, Phillip. Let the games beGay! Stuttgart: Gatzanis, 2005.

BOURCIER, Marie-Hélène. Queer Zones: Politiques des identités sexuelles des représentations et des savoirs. Paris: Éditions Balland, 2001. p. 175-212.

BUTLER, Judith. Problemas de gênero: feminismo e subversão da identidade. Rio de Janeiro: Civilização Brasileira, 2003.

CAMARGO, Wagner Xavier. Circulação do Desejo: esporte, corpos atléticos e práticas de sexo. Revista Textura (ULBRA), v. 17, p. 110-138, 2015.

CAMARGO, Wagner Xavier; RIAL, Carmen S. Competições esportivas mundiais LGBT: guetos sexualizados em escala global? Revista Estudos Feministas, v. 19, n. 3, p. 977-1003, set./dez. 2011.

CAMARGO, Wagner Xavier. 0 universo desportivo de cegos e deficientes visuais: uma interpretação. 1999. 200 f. Dissertação (Mestrado em Educação Física) - Faculdade de Educação Física, Universidade Estadual de Campinas, Campinas, 2000.

CHIMOT, Caroline; LOUVEAU, Catherine. Becoming a man while playing a female sport: The construction of masculine identity in boys doing rhythmic gymnastics. International Review for the Sociology of Sport, v. 45, n. 4, 436-456, Dec. 2010.

COELHO, Johanna. Inserção dos meninos no universo cultural da ginástica rítmica: pesquisaação na Federação Riograndense de Ginástica. 2016. 111 p. (Doutorado em Ciência do Movimento Humano). Escola de Educação Física, Universidade Federal do Rio Grande do Sul, Porto Alegre, 2016.

COLLI, Eduardo. Universo Olímpico: uma enciclopédia das Olimpíadas. São Paulo: Códex, 2004.

COSTA, Carlos Eduardo. Torneios Universitários: disputas e sociabilidade nas práticas esportivas estudantis. In: TOLEDO, Luiz Henrique; COSTA, Carlos Eduardo (Orgs.). Visão de jogo: antropologia das práticas esportivas. São Paulo: Ed. Terceiro Nome, 2009. p. 17-44.

DAVIDSON, Judy. The necessity of queer shame for gay pride: the gay games and cultural events. In: CAUDWELL, Jayne (org.). Sport, Sexualities and Queer/Theory. London/New York: Routledge, 2006. p. 90-105.

DOUGLAS, Mary. Pureza e Perigo. São Paulo: Perspectivas, 1976.

ELIAS, Norbert. O Processo Civilizador. Rio de Janeiro: Jorge Zahar, 1994.

ENG, Heidi. Queer athletes and queering in sport. In: CAUDWELL, Jayne (org.). Sport, Sexualities and Queer/Theory. London/New York: Routledge, 2006. p. 49-61.

ENG, Heidi. Doing Sexuality in Sport. Journal of Homosexuality, v. 54, n.1/2, p. 103-123, 2008.

FEDERATION OF GAY GAMES. Figure Skating, final results. 2006. Disponível em: < http://web. archive.org/web/20071108114932/http://www.gaygameschicago.org/images/Sports/FigureSkating/ results-FigureSkating-hometown.pdf >. Acesso em: 10 nov. 2014.

GASTALDO, Édison. Ritualizações da Nacionalidade entre Torcedores da Copa do Mundo: notas etnográficas. In: ENCONTRO ANUAL DA ANPOCS, 31. 2007. Anais..., Caxambu: ANPOCS, 2007. p. $1-20$.

GATTI, José. Notas sobre Masculinidades. In: PENTEADO, Fernando; GATTI, José (Orgs.).

Masculinidades: teoria, crítica e artes. São Paulo: Estação das Cores e Letras, 2011. p. 9-23. 
HALL, Stuart. A Identidade Cultural na Pós-Modernidade. Rio de Janeiro: DP\&A, 1992.

INTERNATIONAL PARALYMPIC COMMITTEE. Who we are. History of the Movement. 2015.

Disponível em: <http://www.paralympic.org/ThelPC/HWA/HistoryoftheMovement>. Acesso em: 12 dez 2016.

JARVIS, Nigel. Ten men out: gay sporting masculinities in softball. In: CAUDWELL, J. (Org.). Sport, sexualities and queer/theory. London: Routledge, 2006. p. 62-75.

KRISTEVA, Julia. Aproaching abjection In: The powers of horror: an essay on abjection. New York: Columbia University Press, 1982. p. 1-30.

MAUSS, Marcel. As Técnicas do Corpo. In: Sociologia e Antropologia, São Paulo: Cosac e Naify, 2003. p. 211-233.

McRUER, Robert. Compulsory Able-Bodiedness and Queer/Disabled Existence. In: DAVIS, Lennard J. (Ed). The Disability Studies Reader. 2. ed. London: Routledge, 2006. p. 88-99.

McRUER, Robert; WILKERSON, Abby L. Desiring Disability: Queer Theory Meets Disability Studies. Special issue of GLQ. A Journal of Lesbian and Gay Studies, v. 9, n. 1/2, p. 23, 2002.

MOORES, Ezequiel Fernández. Atleta sem pernas, Oscar Pistorius causa polêmica. 2008. Disponível em: < http://terramagazine.terra.com.br/interna/0,,0l2295337-El6583,00.html>. Acesso em: 12 dez 2016.

OSCAR Pistorius not certain of 2012 Olympic place. BBC Sport (Athletics), Nov/2011. Disponível em: < http://news.bbc.co.uk/sport2/hi/athletics/15562204.stm>. Acesso em: 12 dez. 2016.

PRONGER, Brian. Homosexuality and Sport: who's winning? In: MCJAY, Jim; MESSNER, Michel A; SABO, Don. Masculinities, Gender Relations, and Sport. London: Sage, 2000. p. 222-244.

RIAL, Carmen Silvia. Rodar: a circulação dos jogadores de futebol brasileiros no exterior. Horizontes Antropológicos, v. 14, n. 30, p. 21-65, jul./dez. 2008.

$\mathrm{RICH}$, Adrienne. La heterosexualidad obligatoria y la existencia lesbiana. In: NAVARRO, Marysa; STIMPSON, Catherine (Eds). Sexualidad, género y roles sexuales. México: Fondo de Cultura Económica, 1999. p. 159-211.

SOARES, Antônio Jorge Gonçalves; VAZ, Alexandre Fernandez. Esporte, globalização e negócios: 0 Brasil dos dias de hoje. In: DEL PRIORI, Mary; MELO, Victor Andrade de. (Org.). História do esporte no Brasil: do Império aos dias atuais. São Paulo: UNESP, 2009. p. 481-504.

STROHKENDL, Horst. The 50th Anniversary of Wheelchair Basketball. Munster/New York: Waxmann, 1996.

SYMONS, Caroline. The Gay Games: a history. New York: Routledge, 2010.

TRAVERS, Ann. Queering Sport: Lesbian Softball League and the Transgender Challenge. International Review for the Sociology of Sport, v. 41, n. 3-4, 431-446, Dec. 2006.

WADDELL, Tom; SCHAAP, Dick. Gay Olympian: the life and death of Dr. Tom Waddell. New York: Alfred A. Knopf, 1996.

YOUNG, Perry D. Lesbians and Gays and Sports. New York/Philadelphia: Chelsea House Pub., 1995. 
Apoio:

Pesquisa financiada pela Fundação de Amparo à Pesquisa do Estado de São Paulo (FAPESP). 